\title{
Brain Pathways for Learned and Unlearned Vocalizations Differ in Zebra Finches
}

\author{
H. Blair Simpson and David S. Vicario \\ The Rockefeller University, New York, New York 10021
}

\begin{abstract}
Male zebra finches sing, females do not. However, both sexes produce the "long call" when placed in visual isolation. This call is sexually dimorphic; it includes learned components in males but not in females. The 3 learned features of the male long call are a high fundamental frequency, a fast frequency modulation, and a short, stable duration. These features are learned by the male during development, as is song. Since similar features are also found in song syllables, we wanted to know whether long-call production depends on the same CNS pathway that controls song production. Three critical components of the song pathway are telencephalic nuclei HVC, RA, and the tracheosyringeal (ts) nerves innervating the syrinx. In male zebra finches, bilateral section of the ts nerves affected the fundamental frequency and fast frequency modulations of both the long call and song but left the temporal features intact. Ts nerve section had no effect on the female long call. Bilateral lesions of either HVC or RA in males affected the fundamental frequency, fast frequency modulations, and temporal structure of both the long call and song. Similar lesions had no effect on the female long call. These results demonstrate that HVC, RA, and the ts nerves make critical contributions to the acoustic features of the male long call and song, while the temporal pattern depends on HVC and RA but not the ts nerves. HVC and RA lesions remove all the learned features that distinguish the male call and reveal a simple unlearned vocalization shared by both sexes. We suggest that the learned features of oscine songbird vocalizations are controlled by a telencephalic pathway that acts in concert with other pathways responsible for simpler, unlearned vocalizations.
\end{abstract}

Vocal learning can be defined as the modification of vocal output by reference to an external model. In oscine songbirds, the study of vocal learning has focused on song, which is typically learned during development (Nottebohm, 1972; Welty and Baptista, 1988). In most species, it is the male who sings, either in territorial defense or courtship, while the female does not (Nottebohm, 1972; Welty and Baptista, 1988). Discrete brain nuclei critical for song production have been identified (Nottebohm et al., 1976), and sexual differences in their neuroanatomy have

\footnotetext{
Received Aug. 10, 1989; revised Nov. 11, 1989; accepted Dec. 20, 1989.

This work was supported in part by grants from the National Institutes of Health: MS I P grant GMO 7739 (to H.B.S.) and MH40900 (to D.S.V.). We would like to thank Fernando Nottebohm, Darcy B. Kelley, Heather Williams, and Scott Smith for commenting on the manuscript.

Correspondence should be addressed to Blair Simpson, Box 228, The Rockefeller University, 1230 York Avenue, New York, NY 10021.

Copyright (c) 1990 Society for Neuroscience 0270-6474/90/051541-16\$02.00/0
}

been correlated with sexual differences in singing behavior (Nottebohm and Arnold, 1976; reviewed in DeVoogd, 1986). However, since females do not sing, it is unclear whether this neuroanatomical dimorphism reflects sex differences in vocal production or in vocal learning.

The present report addresses this distinction between vocal production and vocal learning by studying the neural substrate for call production in zebra finches. Both males and females produce a variety of calls that are simpler in structure than song, but only the male sings (Immelmann, 1969; Nottebohm and Arnold, 1976; Price, 1979; Zann, 1984; personal observations). We focused on the "long" or "distance" call, because it is produced by both sexes and yet is learned by vocal imitation only in the male (Zann, 1985). The long call of zebra finches is their longest and loudest call; it is produced when zebra finches are visually isolated (Zann, 1984). It develops in both sexes from the same nestling vocalization, but its adult form is sexually dimorphic (Zann, 1984, 1985). The male long call has more complex acoustic features than the female call, making the male long call resemble some song syllables (Price, 1979). Males learn these features by imitating external models: sons imitate the long calls of their zebra finch fathers (Zann, 1985; unpublished observations), and young male zebra finches raised by Bengalese finch foster parents can produce long calls with Bengalese features (Zann, 1985). There is no evidence that the female long call is influenced by external models (Zann, 1985).

To determine which neural structures are involved in the production of learned features of the long call, we lesioned the higher vocal center (HVC), the nucleus robustus archistriatalis (RA), and the tracheosyringeal (ts) nerves in male and female zebra finches. [The higher vocal center (HVC) was heretofore called the hyperstriatum ventralis, pars caudalis ( $\mathrm{HVc}$ ), a misnomer (Nottebohm, 1987).] Because the male long call resembles song syllables, these neural structures were selected: they play a critical role in the production of learned song in canaries (Nottebohm et al., 1976), and it has been assumed they function analogously in zebra finches. The structures are synaptically connected to form the main efferent path of the song control system: HVC projects to RA, which in turn projects to the tracheosyringeal part of the hypoglossal nucleus (nXIIts). Axons of nXIIts motor neurons travel in the ts nerve to innervate the muscles of the syrinx, the bird's vocal organ. HVC, RA, and nXIIts are all sexually dimorphic in zebra finches (Nottebohm and Arnold, 1976; Arnold, 1980; Gurncy, 1981).

We used both male and female zebra finches and focused on the long call in order to determine the contribution these sexually dimorphic structures make to learned versus unlearned features of vocalizations. Moreover, by interrupting the vocal 
pathway at different levels (HVC, RA, and ts nerve), we were able to define the roles these different structures play in vocal production. Our results suggest that the vocal control system of oscine songbirds includes a telencephalic pathway that enables the production of complex, learned vocalizations. This telencephalic pathway must act in concert with additional pathways that govern the production of simpler, unlearned vocalizations.

\section{Materials and Methods}

Forty-one adult zebra finches, Taeniopygia gullala, were used in this study. All birds were purchased from a local supplier or came from our own breeding colony, established from domesticated stock.

Sound recording. Twenty-three male and 18 female birds were recorded in a sound-proof booth or in a double-walled Lucite box to reduce background noise and to control visual contact with other birds. Birds receiving central brain lesions or peripheral nerve sections were recorded both before and after surgery. Recordings were made using either a Tandberg reel-to-reel (Series 15) or a Marantz cassette tape recorder (PMD 221). Long calls were elicited from a bird by permitting it to hear but not see other zebra finches. Song was evoked from males by placing a female within view.

Sound analysis. To generate sonograms for data analyses, calls and songs were low-pass-filtered at $10 \mathrm{kHz}$, digitized at $20 \mathrm{kHz}$, Fouriertransformed, and displayed using an enhanced version of a spectral editing program (originally described by Zoloth et al., 1980) on a DEC LSI 11/73 computer. Computer sonograms were used to measure the fundamental frequency and to inspect frequency modulations of call notes and song syllables. The fundamental frequency was defined as the lowest frequency band that had harmonics at integral multiples. This was measured using the first constant frequency segment; for calls with more than one such segment, we scored the segment with the highest fundamental. The duration was measured from the start to the stop of continuous sound when the call amplitude was displayed on a storage oscilloscope. Sonograms for publication were prepared on a Kay 6061B sonograph machine set for linear display, flat spectral response, and wide bandwidth.

Statistics. Sixteen males and 9 females received central and/or peripheral lesions. Statistical analyses of duration and fundamental frequency were performed on recordings from these birds, comparing each bird to itself before and after lesions. For duration, 25 long calls were sampled sequentially from a single recording session for each bird before and after lesions. In some cases, a single session did not contain 25 calls, and calls from the next appropriate recording session were also used. In 5 cases out of 50 , samples of 25 were not available and smaller samples (13-24) were used. Fundamental frequencies were measured from 5 calls of each bird before and after lesions. Only 5 samples were used because the fundamental frequency was extremely stable; the variability within a bird was less than the resolution of the Fourier transform $(80 \mathrm{~Hz})$. A 2-tailed Mann-Whitney $U$ test was used to determine whether a change in central tendency occurred in either the duration or the fundamental frequency. A 2-tailed $F$ test was used to test whether duration variability changed. For both tests, changes were considered significant at $p<0.05$. The $F$ test was used on all birds. Duration samples were tested for normality by the Kolmogorov-Smirnov 1-sample test: a $p$ value $<0.05$ meant that the sample was not normally distributed. In 2 males, duration samples were not normally distributed prior to surgery, but the deviations from normality were small enough $(p=0.04$, 0.03 ) that the $F$ test was used anyway. For 1 male and 1 female, duration sample size was too small for the Kolmogorov-Smirnov 1-sample test $(n=16,13)$. In these 2 cases, we assumed normality. Statistical analyses of duration and fundamental frequency were also performed on recordings from 4 intact males and 5 intact females as controls.

Central lesions. After the birds were anesthetized with both Ketamine $(30 \mathrm{mg} / \mathrm{kg}$ ) and Xylazine $(40 \mathrm{mg} / \mathrm{kg})$, the skin was opened, and a window in the skull was made over the appropriate brain area. In males, HVC was located by visual inspection: the overlying hippocampus was removed and the fibers streaming out the posterior pole of $\mathrm{HVC}$ towards RA were used as a landmark. In females, HVC was located stereotaxically, using coordinates derived from a stereotaxic atlas of the canary brain (Stokes et al., 1974) and then adjusted for the zebra finch brain in pilot experiments. Bilateral suction lesions of $\mathrm{HVC}$ were made in 5 males and 3 females using a pasteur pipette narrowed and flame-polished at the tip. Brain tissue was sucked into the pipette by vacuum until HVC and a surrounding area were removed. In both sexes, suction lesions proved to be an effective and efficient method of ensuring the complete destruction of HVC.

In males, the location of nucelus RA was approximated using stereotaxic coordinates and confirmed electrophysiologically by the pattern of spontaneous activity and presence of multiunit auditory responses to noise bursts (Williams, 1985). In females, RA was located stereotaxically because electrical activity proved less reliable than in males. Bilateral electrolytic lesions of RA were made in 3 males and 3 females using insect pins insulated except at the tip (size 000; InsL-x Products Corp.). Another 2 males received bilateral RA lesions using tungsten microelectrodes (Micro Probe Inc.). For all lesions with insect pins, 90 $\mu \mathrm{A}$ of anodal DC current was passed for 1.5-2 min at each lesion sile. Two to four sites per side in males destroyed RA and an area surrounding it. In females, because we could rely only on stereotaxic coordinates, 4-6 sites per side were used to insure that RA was destroyed. For lesions with tungsten microelectrodes, $10 \mu \mathrm{A}$ of current was passed for $20 \mathrm{sec}$ at 3-6 sites per side.

Chemical lesions of HVC and RA were attempted in 2 males by pressure-injecting kainic acid (Sigma) into the brain bilaterally. In 1 male, $55 \mathrm{nl}$ of $0.1 \%$ kainic acid was injected stereotaxically into the region of HVC on each side. The other male received a $15 \mathrm{nl}$ injection of $1 \%$ kainic acid into RA on each side, after RA was located as described above.

Tracheosyringeal nerve section. To section the ts nerves, birds were first anesthetized with Metofane, and an incision was made in the skin of the neck, exposing the ts nerves as they run along each side of the trachea. The nerves were cut at a point approximately equidistant between the syrinx and the larynx. At least $2 \mathrm{~mm}$ of nerve was removed from each side, sufficient to prevent regrowth in the period before death (unpublished observations). Because the ts nerve innervates the tracheolateralis muscle as well as the syrinx, nerve section completely or partially denervated this muscle as well. Four males and 3 females received bilateral nerve sections. Two of these male birds received subsequent central lesions: one, of HVC; the other, of RA, by the methods described above.

Histological examination. Most birds were killed 1-3 weeks after central lesions and up to a week after nerve section. Two male birdsone with bilateral HVC lesions, the other with bilateral RA lesionssurvived over a month before death.

After final recordings, all lesioned birds were anesthetized with an overdose of Ketamine and Xylazine, and then perfused with $20 \mathrm{ml}$ of $0.9 \%$ saline followed by $20-50 \mathrm{ml}$ of $10 \%$ formol saline. The brains were removed and postixed in $10 \%$ formol saline from $1 \mathrm{~d}$ to 2 weeks. Sagittal sections, $50 \mu \mathrm{m}$, were cut on a Vibratome (Technical Products International, Inc., Series 1000), mounted on glass slides, and stained with cresyl violet. The tissue was examined using a Nikon microscope. The extent of each lesion was determined from camera lucida drawings of each brain, and representative sections were photographed.

Figure 1. Long calls of male and female zebra finches. A, Long calls of 5 adult male zebra finches. Open arrows point to fast frequency modulations; solid arrows, the fundamental frequency. $i$, Call showing all 3 male-typical features: short duration, fast frequency modulation, and relatively high fundamental frequency. $i i$, Call showing all 3 male-typical features, with the fast frequency modulation at the end. iii, Call with 2 male-typical features: a fast frequency modulation and short duration. $i v$, Call with 2 male-typical features: a short duration and relatively high fundamental frequency. $v$, Complex call (described fully in Fig. $8 B$ ). B, Long calls of 3 adult female zebra finches $(i-i i i)$ showing their simpler acoustic structure, including a lower fundamental frequency (solid arrows) than the average for male long calls, and no downward fast frequency modulation as seen in male calls. $C$, Female-like long call produced by a male. $D$, Female long call with a fast frequency modulation (open arrow) at call onset similar to but less pronounced than that seen in male long calls. Time bar, $150 \mathrm{msec}$. 

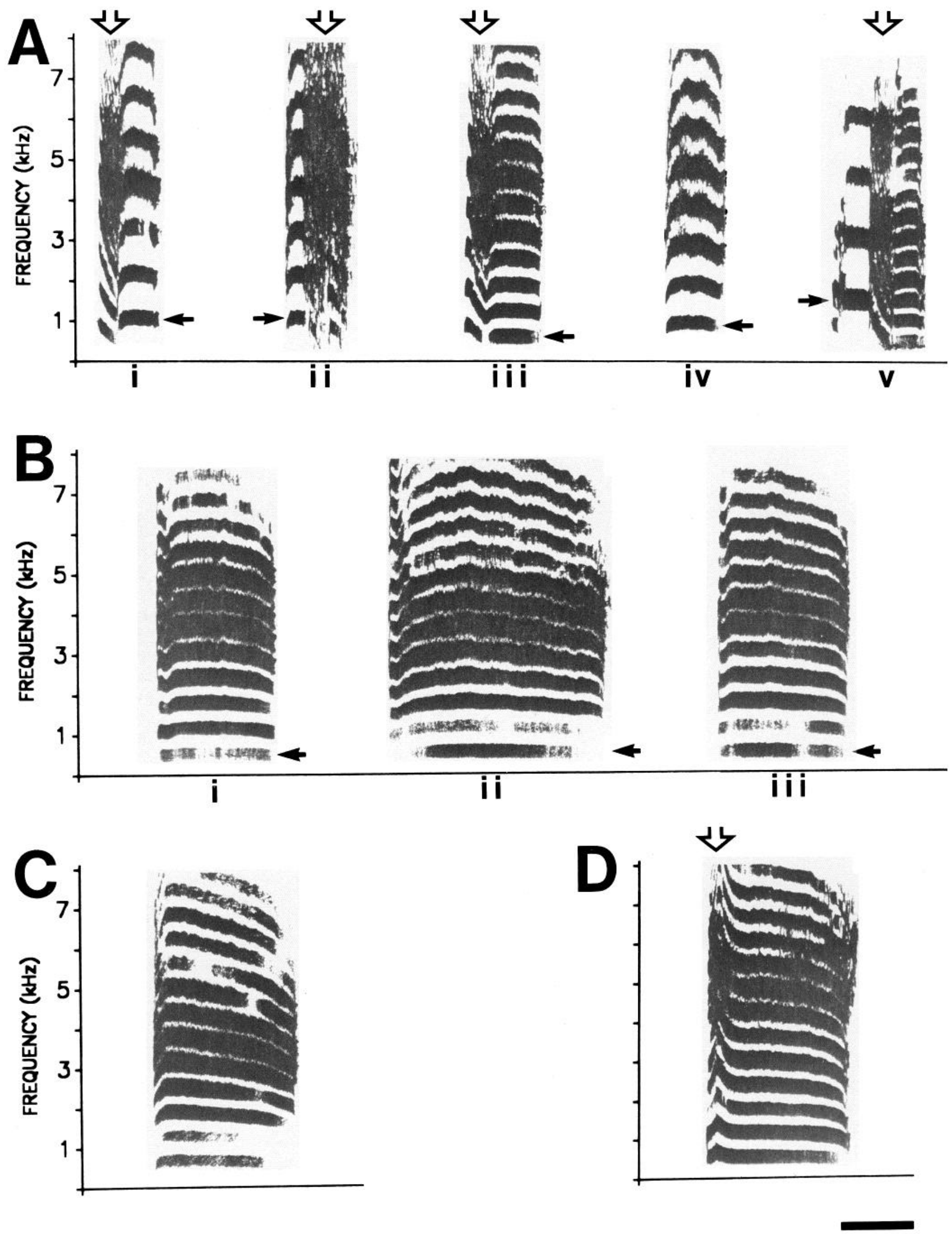

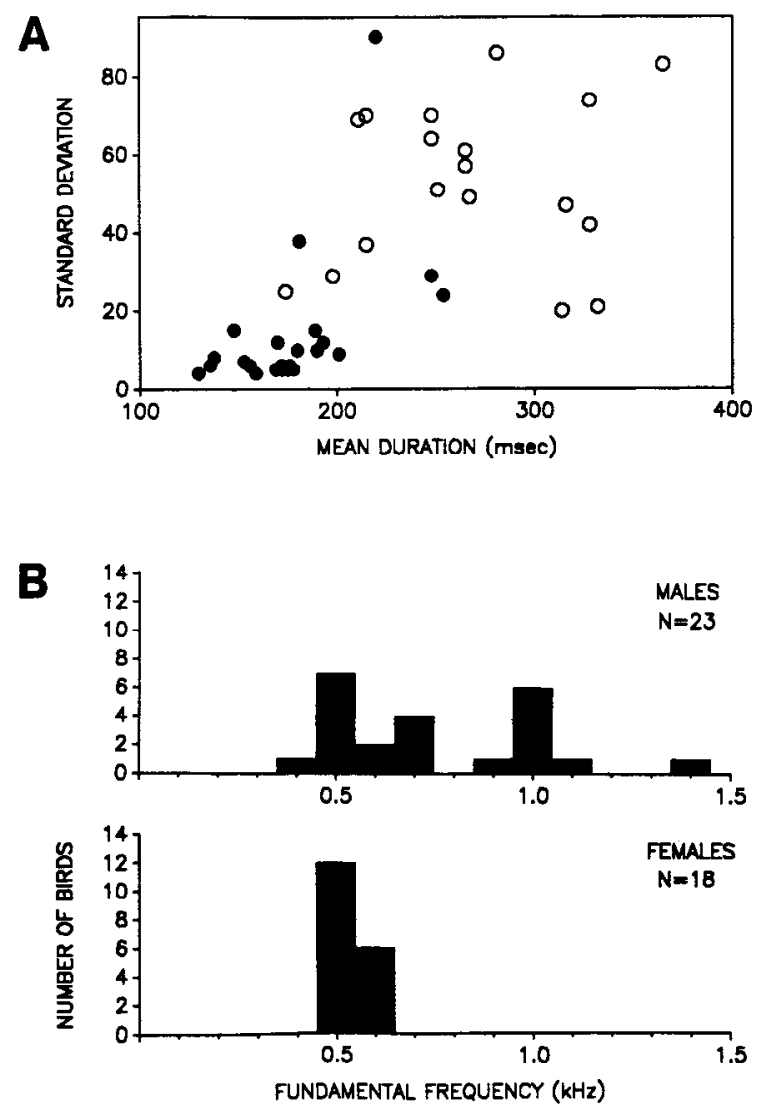

Figure 2. Differences between males and females in 2 key features of the long call. $A$, Mean duration and SD are plotted for 23 males (filled circles) and 18 females (open circles). Most males produce long calls with shorter, more stable durations than females $(n=25$ for each bird except in 4 cases, where $n=24,23,19,16)$. $B$, Histograms of mean fundamental frequencies ( $n=5$ for each bird) for 23 males and 18 females. Whilc some male long calls have fundamental frequencics like those seen in female long calls, other males produce long calls with an elevated fundamental frequency relative to females.

\section{Results}

Description of the "long" ("distance") call

We first assessed the long calls of 23 intact male and 18 intact fcmalc zcbra finches to provide a basis for the study of these calls following brain lesions or peripheral nerve section. When isolated visually but not acoustically from other birds, adult male and female zebra finches emit short, medium, and long calls (Price, 1979). The "long" call is the longest and loudest call emitted by zebra finches (Price, 1979; Zann, 1984). Examples of typical male and female long calls are shown in Figure 1 .

Male long calls were distinguished from female long calls by 3 characteristic features, originally described by Zann (1984): a shorter and more stable duration; a higher fundamental frequency in the tonal (or constant frequency) part of the call; and a segment with a rapid frequency modulation, in the form of a downsweep, hereafter called a fast frequency modulation (Fig. $1 A$, i). Zann (1985) showed that males learn these features during development by imitating adult models. However, he called the fast frequency modulation a noise clement. Sometimes the fast frequency modulation resembles noise when the call is displayed at high gain or when the modulations occur for frequency bands above $5000 \mathrm{~Hz}$. Clayton (1988) also identified these features but used terminology that conflicts with Zann's.

In our population, males differed in the characteristic features their long calls contained. Most males (19/23) produced long calls with at least 2 of these malc-typical features, although different males produced calls with all possible combinations of the features (e.g., Fig. 1 $A$, iii, iv). The long call of one male lacked all male-typical features and was female-like in all respects (Fig. 1C). This variety differs dramatically from the monomorphism Zann reported (1984). Using wild-caught birds from Australian flocks, Zann reported that $99 \%$ of his male T.g. castanotis calls had all 3 characteristic features and were of the type shown in Figure $1 A$ ii, a form rare in our sample (1/23). In our population, in contrast to Zann's, the fast frequency modulation occurred more often at the beginning of the call than at the end.

The typical female long call we recorded lacked all 3 characteristics of male long calls: it had a lower fundamental frequency than the male average and did not have a fast frequency modulation or a short, stable duration (Fig. $1 B$ ). It closely resembled the female call described by Zann (1984). The longest call each female produced was longer than any normal male call and has been considered the typical female "long" call (see Zann, 1984). However, females also produce calls similar in acoustic structure to their longest call, but shorter in length. For example, one female produced acoustically similar calls that ranged from 169 to $470 \mathrm{msec}$ in duration. All these calls had the same fundamental frequency and were given under the same recording conditions. For the purposes of this report, we considered female long calls to be loud calls longer than $125 \mathrm{msec}$ (Price, 1979). This criterion was applied to male long calls after lesions as well (see below). Two of 18 females produced long calls with a rapid downward frequency modulation at call onset, similar to that seen in male long calls but much less pronounced (Fig. $1 D$ ).

The mean duration and SD for the 23 males and 18 females recorded are plotted in Figure $2 A$, illustrating that most males had a short and stable duration relative to female long calls. The mean duration of the male long call was $178 \mathrm{msec}$ (range of individual bird means: $130-254 \mathrm{msec}$ ), while that of the female call was $268 \mathrm{msec}$ (range of individual bird means: 174$365 \mathrm{msec}$ ). The duration of the male long call was significantly shorter than that of the female call when individual means were used to compare sex differences (Mann-Whitney $U: z=4.7 ; p$ $<0.001$ ). These means were calculated using 25 calls per bird (except in 4 cases, where only $24,23,19$, and 16 were available). For an individual female, all calls used had the same acoustic structure as the longest call she produced.

The distribution of fundamental frequencies for these same males and females is shown in Figure 2B, illustrating that many males had a constant frequency segment in their calls with an elevated fundamental frequency while females did not. The mean fundamental frequency of the male long call was $804 \mathrm{~Hz}$ (range of individual bird means: $477-1419 \mathrm{~Hz}$ ), while that of the female call was $568 \mathrm{~Hz}$ (range of individual bird means: 516-645 Hz). The fundamental frequency of the male long call was significantly higher than that of the female call when individual means were used to compare sex differences (Mann-Whitney $U: z=$ $3.1 ; p<0.002$ ). These means were calculated using 5 fundamentals from each bird.

Individual zebra finches produced a uniquc long call that was stable over time. For example, 4 males were recorded twice from 3-20 d apart. None of the 4 showed a significant change 
Table 1. Effect of ts nerve section on key features of the long calls of 3 females and 4 males

\begin{tabular}{|c|c|c|c|c|c|c|c|c|c|}
\hline \multicolumn{5}{|c|}{ Before nerve section } & \multicolumn{5}{|c|}{ After nerve section } \\
\hline BIRD & FFM & FF & DUR & VAR & FFM & FF & DUR & VAR & TIME \\
\hline \multicolumn{10}{|c|}{ Females } \\
\hline $\mathrm{Fa} 5$ & no & 606 & 267 & 2424 & no & $593 \quad(U=8.5)$ & $258 \quad(z=0.3)$ & $1771(F=1.4)$ & $5-6$ \\
\hline $\mathrm{Fa} 3$ & no & 581 & 265 & 3671 & no & $555 \quad(U=7.5)$ & $233^{*}(z=2.0)$ & $1788(F=2.1)$ & $6-7$ \\
\hline $\mathrm{Fa} 20$ & no & 516 & 365 & 6859 & no & $490 \quad(U=7.5)$ & $337 \quad(z=0.1)^{c}$ & $10,223(F=1.5)$ & 6 \\
\hline \multicolumn{10}{|l|}{ Males } \\
\hline N14 & yes $^{d}$ & 1032 & 180 & 101 & no & $581^{* *}(U=0)$ & $181 \quad(z=0.2)$ & $65(F=1.6)$ & $2-3$ \\
\hline $\mathrm{N} 27$ & no & 581 & 254 & 576 & no & $581 \quad(U=12.5)$ & $298^{* *}(z=4.4)$ & $1077(F=1.9)$ & 2 \\
\hline
\end{tabular}

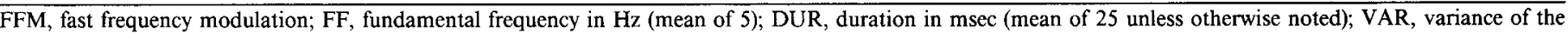

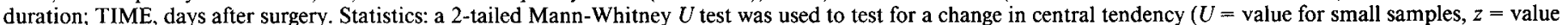

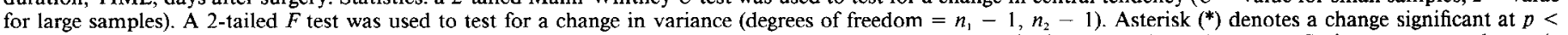

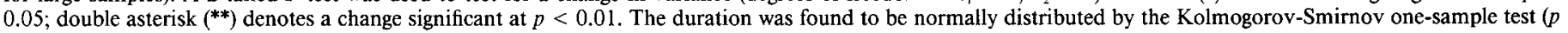
$<0.05$ ) unless noted.

${ }^{a}$ Duration was not normally distributed $(0.03<p<0.04)$.

${ }^{\circ} 18<n<25$.

${ }^{c} n=13$ or 16 , and the sample was too small for the Kolmogorov-Smirnov test.

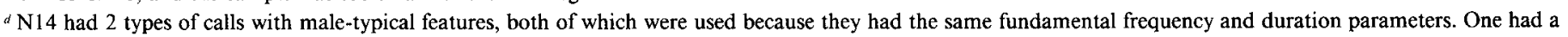
FFM, the other did not.

in the mean duration, duration variability or fundamental frequency of the long call. Five females were recorded twice from 1-40 d apart. The long calls of 2 birds, comparing recordings 1 and $6 \mathrm{~d}$ apart, respectively, showed a significant change in mean duration, in one case increasing, the other decreasing. However, none of the 5 produced long calls with a significant change in duration variability or fundamental frequency.

Most birds produced a single form of long call, but some male birds (6 of 23) also produced variants that occurred infrequently $(<20 \%$ in a sample of 25$)$. One variant involved doubling or halving the call: either the bird routinely produced its long call as a singlet and, as a variant, produced a doublet ( 2 birds), or the bird routinely produced its call as a doublet and as a variant, produced a singlet ( 1 bird). Another variant observed was the occasional production of a call longer than $125 \mathrm{msec}$ that was without any male-typical features and thus resembled a female long call ( 4 birds). One of the 6 males was notable because he produced 3 different calls that could be distinguished from the short call: one had a high fundamental frequency and short stable duration typical of the male long call (Fig. $3 C$, i); the second had the same high fundamental frequency and short duration but with a fast frequency modulation at the end (ii); and the third had the fundamental frequency and acoustic structure of a female long call, but was shorter in duration (iii). In a sample of 25 long calls, the female type occurred 3 times, and the 2 male types each occurred 11 times. For our lesion studies, we used males with at least 2 male-typical features and without variants, with 3 exceptions. Of the 9 females we used, one had a slight initial fast frequency modulation.

\section{Effects of peripheral and central lesions}

\section{Effect of $t$ s nerve section}

Females. Bilateral section of the ts nerves in 3 females had no major effects on the female long call. Long calls from one of these females before and after nerve section are shown in Figure $3 A$. The effects on key features of the long call for all females are shown in Table 1 . Nerve section had no significant effect on fundamental frequency in any of these females. Nerve section had minimal effects on long-call duration. Two females produced long calls after nerve section whose duration did not differ significantly from before; one produced calls whose duration was significantly shorter $(p=0.043)$. However, mean duration is not a stable measure in intact females: 2 of 5 control females also had a significant change in mean duration over a similar time span. Finally, no significant change in duration variability occurred in long calls of any of these females.

Males. A. LONG CALL: Bilateral section of the ts nerves in 3 males altered 2 of the 3 characteristic features of the male long call: the downward fast frequency modulation and the relatively high fundamental frequency. Long calls from one of these males illustrating these changes are shown in Figure $3 \mathrm{~B}$. Changes in key features of the long call for all males are displayed in Table 1. The segment of the long call that initially contained the fast frequency modulation was replaced by a segment of relatively constant frequency separated from the rest of the call by a brief drop in frequency. The fundamental frequency of the long calls of 2 of these males dropped significantly and into the female range. The fundamental frequency of the third male's long call started in the female range and did not significantly change.

Nerve section affected long-call duration but not duration variability. The mean duration of the call lengthened slightly $(3.9,2.9$, and $0.6 \%)$ in all males. In 2 of these, this slight increase in duration was statistically significant. Duration variability did not significantly change in any of these males.

The different effect of ts nerve sections on male and female acoustic structure is clearly illustrated by the male that had both male- and female-like calls before nerve section (Figure $3 C$, iiii). As described above, after nerve section, the fundamental frequency of the male-like calls dropped into the female range, the duration lengthened slightly, and the fast frequency modulation that occurred in one of the male-like calls was affected. In contrast, the femalc-like call remained relatively unchanged.

The male with only a female-like long call also received a bilateral nerve transection (N27, Table 1). No significant change 

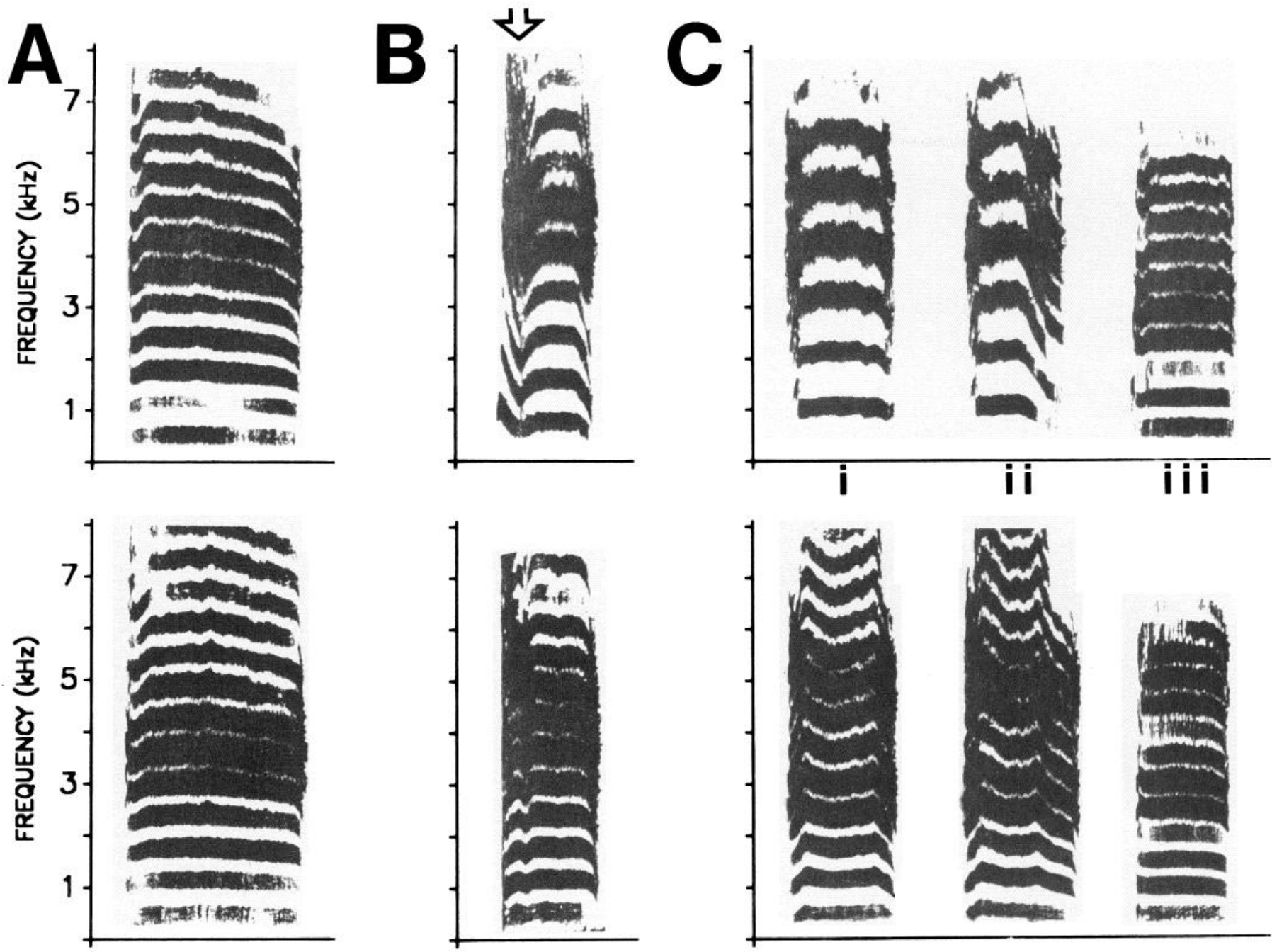

Figure 3. Effect of ts nerve section on female and male long calls. A, Long calls of one female (Fa20) before (top) and after (bottom) nerve section showing no change. $B$, Long calls of one male (N36) before (top) and after (bottom) nerve section, illustrating a change in the beginning fast frequency modulation (open arrow), a drop in fundamental frequency, and a slight increase in duration. After nerve section, this call appears to be composed of 2 separable constant frequency components, one corresponding to the period of the original fast frequency modulation. $C$, Three types of calls of one male (N14) before (top) and after (bottom) nerve section. Nerve section affected the male-typical features in the male-like calls $(i, i i)$ but left the female-like call relatively unchanged (iii). Time bar, $150 \mathrm{msec}$.

in fundamental frequency or duration variability occurred. The mean call duration increased significantly.

B. soNG: Tracheosyringeal nerve section dramatically affected the syllable structure but not the overall temporal pattern of male song. The song of one male before and after nerve section is shown in Figure 4A. Like male long calls, some song syllables are characterized by downward fast frequency modulations, relatively high fundamental frequencies, and/or short durations. After nerve section, song syllables lost these fast frequency modulations and the fundamental frequencies dropped. Many syllables lengthened slightly, thus increasing the duration of the overall song. Nonetheless, the sequence of syllables remained unchanged and stereotyped.

Some birds use call notes in their song (Price, 1979). The male shown in Figure 4 had a song syllable identical to his long call ( $4 A$ vs $4 B$, top). The changes seen in this note after nerve tran- section were the same whether the note appeared in song or as a long call ( $4 A$ vs $4 B$, bottom).

The male with the female-like long call mentioned above had song syllables with fast frequency modulations, high fundamental frequencies, and short durations. Sectioning the nerves had no effect on the long call but altered the song syllables as described above.

\section{Effects of RA lesions}

After receiving bilateral RA lesions, all birds continued to produce long calls. The call amplitude was sometimes decreased for a few days after surgery.

Females. A. LESIONS: Three females received bilateral electrolytic lesions of RA. In all 3 cases, no evidence of RA remained after surgery. The lesions also extended to much of the archistriatum surrounding RA. On at least one side in all 3 birds, 

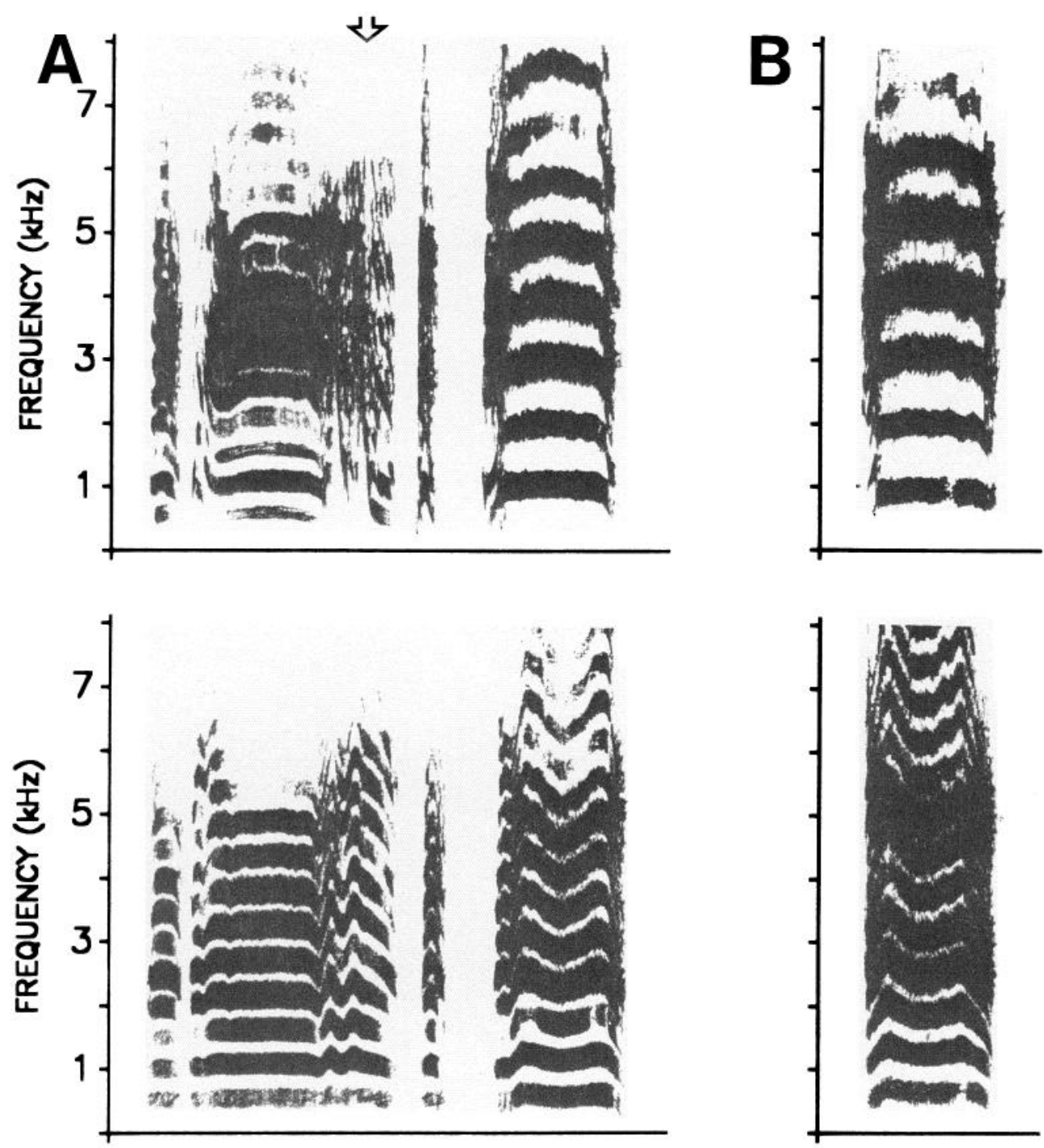

the lesion also extended above the lamina archistriatalis dorsalis into the neostriatum overlying RA. Because the lesions were made with multiple electrode penetrations, they were irregular in shape. However, the maximal diameter of the lesions ranged from 1.2 to $1.7 \mathrm{~mm}$ in the 3 birds. Lesions were roughly similar on both sides. A representative section from one of these females is shown in Figure $5 A$.

B. LONG CALL: In 2 females, lesions of RA and the surrounding area had no significant effect on the female long call. Long calls from one of these females before and after surgery are illustrated in Figure $6 \mathrm{~A}$. No significant change in the fundamental frequency, mean call duration, or duration variability occurred in either female, as shown in Table 2.

A third female (G30) also received a bilateral lesion of RA and the surrounding archistriatum. This female was 1 of the 2 atypical females whose long calls had a slight downward fast frequency modulation at the beginning of the call. The lesion affected the fast frequency modulation as shown in Figure $6 B$. However, like the 2 females described above, neither the fundamental frequency nor the variability of call duration changed significantly following RA lesion, as shown in Table 2 . The mean duration did change significantly, but such a change was also seen in 2 of 5 control females over a similar time span.

Males. A. LESIONS: Five males received bilateral electrolytic lesions of RA. In 2 of the males (N26, Ph27), the lesions of RA were complete and roughly similar on both sides of the brain. In both birds, the maximal diameter of the lesions was approximately $1 \mathrm{~mm}$. The archistriatum just dorsal and ventral to RA was also affected. In one ( $\mathrm{Ph} 27)$, the lesion also extended dorsally into the neostriatum on the right side. In a third male (O1), RA was completely lesioned on the left, but the rostral, medial pole of RA was partially spared on the right. On the left, the lesion was $1.3 \mathrm{~mm}$ in diameter and extended into the surrounding archistriatum and neostriatum. On the right, the lesion was 0.6 $\mathrm{mm}$ in maximal diameter and was limited to RA and the archistriatum just ventral to it. In a fourth male (N95), RA was more than $85 \%$ lesioned on both sides. The maximal diameter of the lesions was about $0.8 \mathrm{~mm}$, and they were almost entirely restricted to RA. Finally, the fifth male (NC4) received a partial lesion of RA. On both sides, the lesion only affected the dor- 

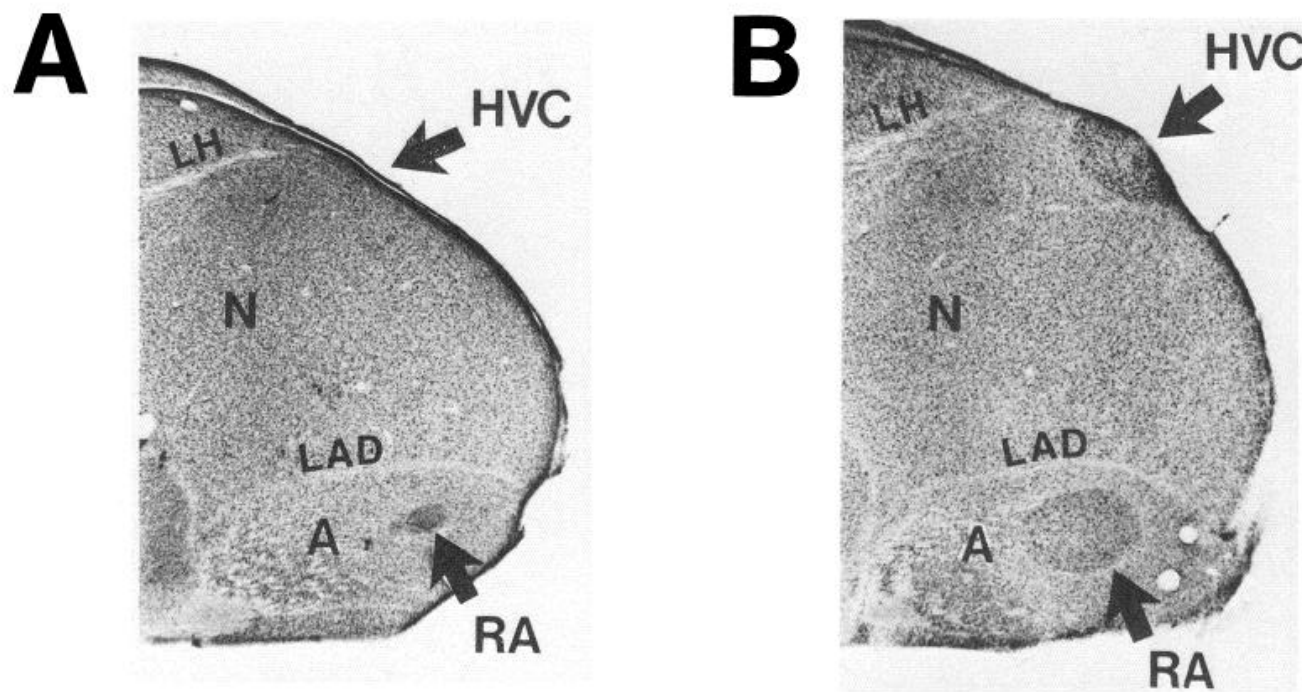

Figure 5. Photomicrographs of central lesions. Sagittal sections $(50 \mu \mathrm{m}$ in thickness) of the caudal pole of the telencephalon of females $(A)$ and males $(B)$. The tissue was stained with cresyl violet. $A$ : Top, Section from an intact female illustrating the position of RA. HVC can be difficult to recognize in females. Middle, Section from one of the females (G30) receiving an electrolytic lesion of RA and the vicinity. This lesion was $1.7 \mathrm{~mm}$ in diameter at its largest extent. Bottom, Section from the female (W194) whose calls are displayed in Figure $8 A$, illustrating a suction lesion in the area of HVC. This lesion extended up to $3 \mathrm{~mm}$ in both the anterior-posterior and the medial-lateral direction, and up to $1.3 \mathrm{~mm}$ in depth. B: Top, Section from an intact male illustrating the position of HVC and RA. Middle, Section from the male (N26) whose calls are displayed in Figure $6 C$, illustrating an electrolytic lesion in the area of RA. This lesion was 1.0 $\mathrm{mm}$ in diameter at its largest extent. Bottom, Section from the male (R38) receiving one of the smallest suction lesions of HVC. This lesion was up to 1.3 $\mathrm{mm}$ in width and length and up to 1 $\mathrm{mm}$ in depth. Scale bar, $1 \mathrm{~mm}$.
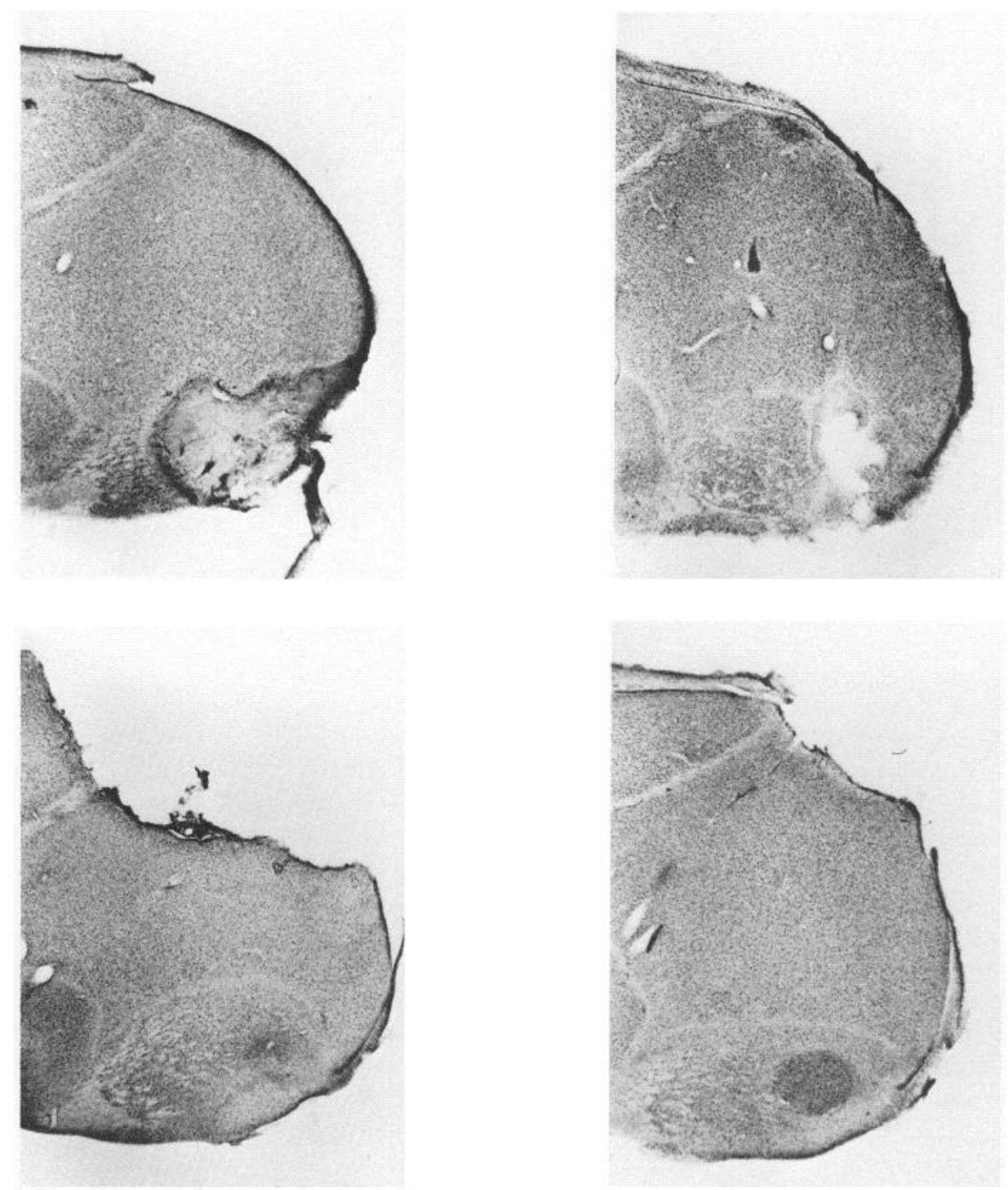
Table 2. Effect of bilateral lesions of an area including RA on key features of the long calls of 3 females and 6 males

\begin{tabular}{|c|c|c|c|c|c|c|c|c|c|}
\hline \multicolumn{5}{|c|}{ Before RA lesion } & \multicolumn{5}{|c|}{ After RA lesion } \\
\hline BIRD & FFM & $\mathrm{FF}$ & DUR & VAR & FFM & FF & DUR & VAR & TIME \\
\hline \multicolumn{10}{|l|}{ Females } \\
\hline $\mathrm{Fa} 17$ & no & 581 & 198 & 814 & no & $581 \quad(U=12.5)$ & $202 \quad(z=0.5)$ & $1766 \quad(F=2.2)$ & 17 \\
\hline $\mathrm{Fal}$ & no & 516 & 248 & 4966 & no & $516 \quad(U=12.5)$ & $235 \quad(z=0.7)$ & $2426 \quad(F=2.0)$ & 6 \\
\hline G30 & yes & 516 & 251 & 2649 & no & $516 \quad(U=12.5)$ & $222 *(z=2.3)$ & $2089 \quad(F=1.3)$ & 6 \\
\hline \multicolumn{10}{|l|}{ Males } \\
\hline $\mathrm{N} 26$ & yes & 774 & $178^{a}$ & 23 & no & $516^{* *}(U=0)$ & $242^{* *}(z=4.6)$ & $4421^{* *}(F=192)$ & $22-23$ \\
\hline Ph27 & yes & 645 & 172 & 35 & no & $593^{*}(U=2.5)$ & $199^{* *}(z=3.5)$ & $1280^{* *}(F=37)$ & 7 \\
\hline $\mathrm{O} 1$ & yes & 710 & 137 & 79 & no & $516^{* *}(U=0)$ & $219^{* *}(z=5.6)$ & $1144^{* *}(F=14)$ & $3-5$ \\
\hline N95 & yes & 1032 & 189 & 218 & no & $645^{* *}(U=0)$ & $183 \quad(z=1.1)$ & $779^{* *}(F=3.6)$ & 17 \\
\hline Nc4 \% & yes & 645 & $201^{b}$ & 85 & yes & $581^{* *}(U=0)$ & $267^{* *}(z=4.7)$ & $3331^{* *}(F=39)$ & $21-25$ \\
\hline $\mathrm{Ph} 23 \%$ & yes & 1032 & $130^{h}$ & 13 & no & $516^{* *}(U=0)$ & $130 \quad(z=0.1)^{r}$ & $19 \quad(F=1.5)$ & $8-9$ \\
\hline
\end{tabular}

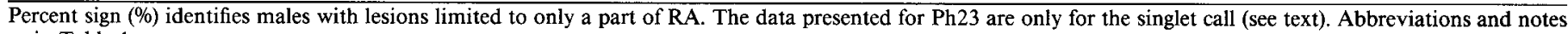
as in Table 1 .

socaudal pole of RA and was centered on the lamina separating the archistriatum from the neostriatum. In all 5 males, the tracks made by the lesioning electrodes were caudal to HVC, and HVC appeared intact. A representative section from one of these males is shown in Figure $5 B$.

B. LONG CALL: All characteristic features of the long call changed in the 2 males with complete electrolytic lesions of RA and the 1 male with a complete RA lesion on the left with partial sparing on the right. After surgery, their long calls lacked the fast frequency modulations seen in their preoperative long calls; the fundamental frequency dropped significantly and into the female range; and both the central tendency and the variability of the long call's duration increased significantly. Calls of one of these males, illustrating these changes, are displayed in Figure $6 C$. Changes in the key features of the long calls for each male are displayed in Table $2(\mathrm{~N} 26, \mathrm{Ph} 27, \mathrm{O} 1)$.

In 3 males receiving incomplete lesions of RA, only some features of the long call were affected. In the male with bilateral lesions of more than $85 \%$ of RA (N95), all characteristic features of the long call except for the mean duration changed significantly (Table 2). In contrast, the male in which only the dorsocaudal pole of RA was lesioned (NC4) produced long calls whose fundamental frequency dropped slightly but significantly and whose mean duration and duration variability increased significantly. However, there was no effect on the fast frequency modulation.

Finally, 1 male $(\mathrm{Ph} 23)$ received a chemical lesion of $\mathrm{RA}$, which appeared to be incomplete, followed by bilateral ts nerve transection. Before central lesion, he produced long calls with all 3 male characteristic features, often delivering the long call as a doublet, sometimes separated and sometimes fused (Fig. $7 A$, top). After partial RA lesion, he continued to produce long calls with the same temporal features as his preoperative calls, still producing these calls in pairs and fused (Fig. $7 \mathrm{~A}$, middle). Moreover, the mean duration and duration variability of the singlet long call did not change significantly. In contrast, the fast frequency modulation was affected, and the fundamental frequency dropped significantly and into the female range, as shown in Table 2. After subsequent nerve section, he produced only one type of long call, which was female-like in all features (Fig. $7 A$, bottom).

C. SONG: After complete or nearly complete RA lesion, no male was observed to sing either spontaneously or when presented with a female despite displaying other behavioral signs of courtship, such as a characteristic posture, dancing, and billwiping (Morris, 1953). One of these birds had a long call identical to a note in his song. After RA lesions, he produced the note as a long call, albeit altered as described above for other birds, but he never sang.

Both the male receiving an electrolytic lesion of only the dorsal caudal cap of RA and the male with the partial chemical lesion of RA sang after surgery. Only the latter was successfully recorded. After this partial chemical lesion, his song syllables lost most of their characteristic acoustic features, but the song's temporal pattern was grossly preserved (Fig. $7 B$, top vs middle). These changes in the song parallel the changes described above for the long call. After subsequent nerve section, the song syllables degenerated into harmonic stacks, and silent spaces in between some song syllables filled in, but again the overall temporal pattern of song was preserved (Fig. 7B, bottom).

\section{Effects of $H V C$ lesions}

After receiving $\mathrm{HVC}$ lesions, both male and female zebra finches continued to produce long calls. The call amplitude was sometimes decreased for a few days after surgery.

Females. A. LESIONS: Three females received bilateral HVC lesions. After surgery, HVC was not present in any of the 3 . In all cases, the overlying hippocampus and the surrounding neostriatum were also destroyed. The maximal anterior-posterior extent of the lesions ranged from 1.3 to $3 \mathrm{~mm}$. In all cases, the lesion extended at least $1 \mathrm{~mm}$ posterior to the lamina hyperstriatica which demarcates the most anterior border of HVC. The maximal depth ranged from 1 to $1.3 \mathrm{~mm}$ and the maximal medial-lateral extent of the lesions ranged from 1.5 to $3.0 \mathrm{~mm}$. In 2 birds, the dorsal caudal pole of Field L, an auditory area of the forebrain in songbirds, may also have been affected. Any fibers from nucleus magnocellularis of the anterior neostriatum (MAN) to RA traveling by HVC could also have been affected. The area of nucleus interfacialis of the neostriatum (NIf) was spared in all 3 birds. A representative section from the female with the largest lesion is shown in Figure $5 \mathrm{~A}$.

B. LONG CALL. Lesions of HVC and the surrounding area had no consistent effect on the long call in the 3 females studied. Calls from one of these females are shown in Figure $8 \mathrm{~A}$. The 

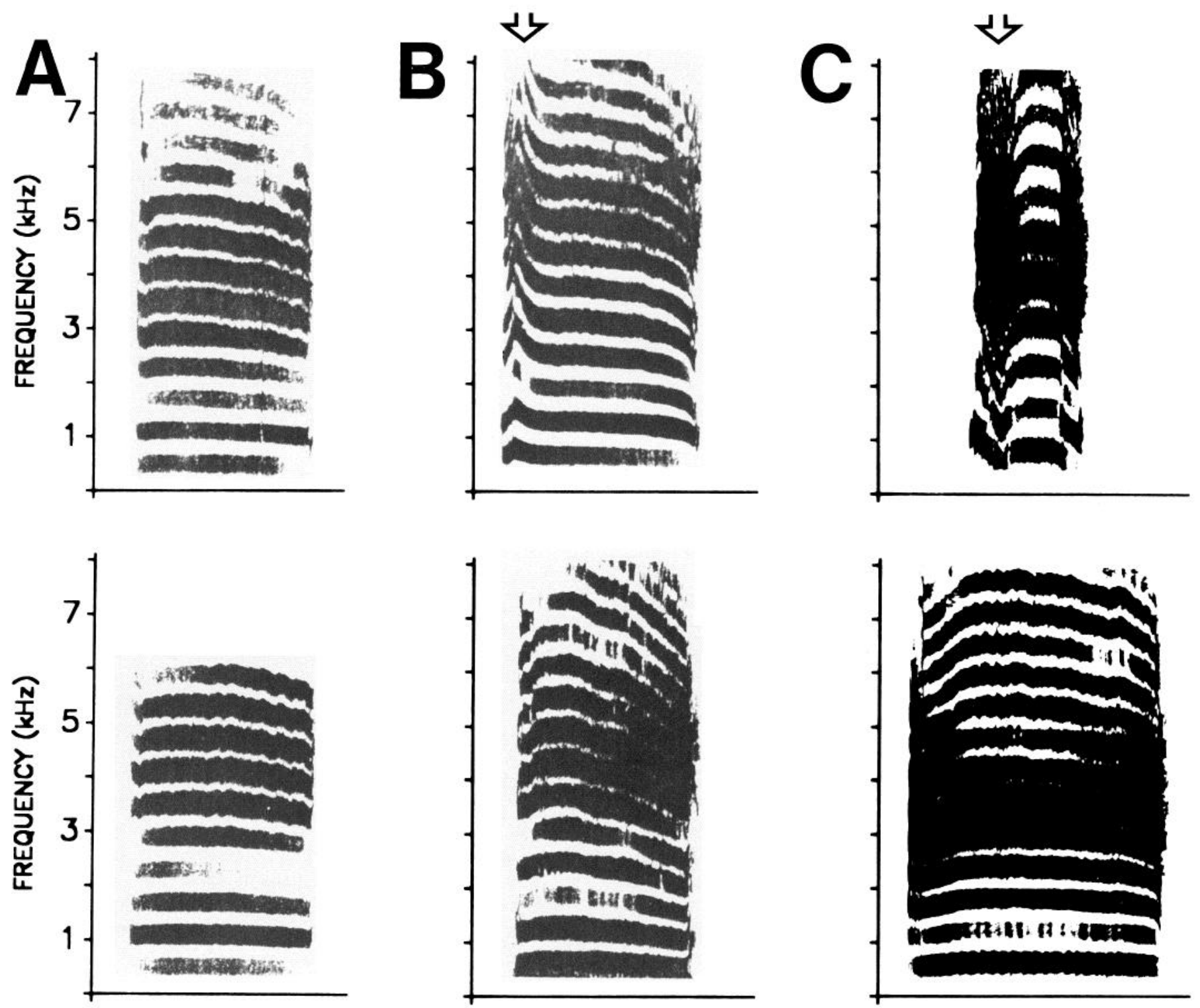

Figure 6. Effect of RA lesions on female and male long calls. A, Long calls of one female (Fa1) before (top) and after (bottom) bilateral RA lesions, showing no change in the call. B, Long calls of one of the atypical females (G30) before (top) and after (bottom) bilateral RA lesions. RA lesions affected the initial frequency modulation (open arrow). C, Long calls of one male (N26) before (top) and after (bottom) RA lesions, illustrating the loss of the fast frequency modulation (open arrow), the increased duration of the call, and the lowering of the fundamental frequency. Time bar, $150 \mathrm{msec}$.

effects on key features of the long calls for all 3 females are displayed in Table 3. Neither the fundamental frequency nor duration variability significantly changed following $\mathrm{HVC}$ lesions. The effect on the central tendency of the duration was inconsistent: in one female, no significant change occurred; in one, the duration was significantly shorter; and in the third, it was significantly longer. Two of 5 control females also showed a significant change in call duration over a similar time span.

Males. A. LESIONS: Five males received bilateral suction lesions of HVC. In 4 of the 5, HVC was completely lesioned bilaterally. In one (R34), the ventral caudal pole of HVC was partially spared on the right side. In 4 males (N15, N21, R34,

Figure 7. Effect of partial RA lesions. Long calls $(A)$ and song $(B)$ of one male $(\mathrm{Ph} 23)$ before (top), after partial RA lesions (middle), and after subsequent bilateral nerve section (bottom). Before surgery, this bird produced male-typical long calls both in pairs ( $i$ ) and fused (ii). Partial RA lesions spared the temporal pattern of both the long calls and the song but affected the fast frequency modulations and the high fundamental frequencies of both. Subsequent nerve section further affected the fast frequency modulations of the call and song, and also affected the way song is divided into syllables. However, the overall temporal pattern of song was preserved. Time bar, $150 \mathrm{msec}$. 

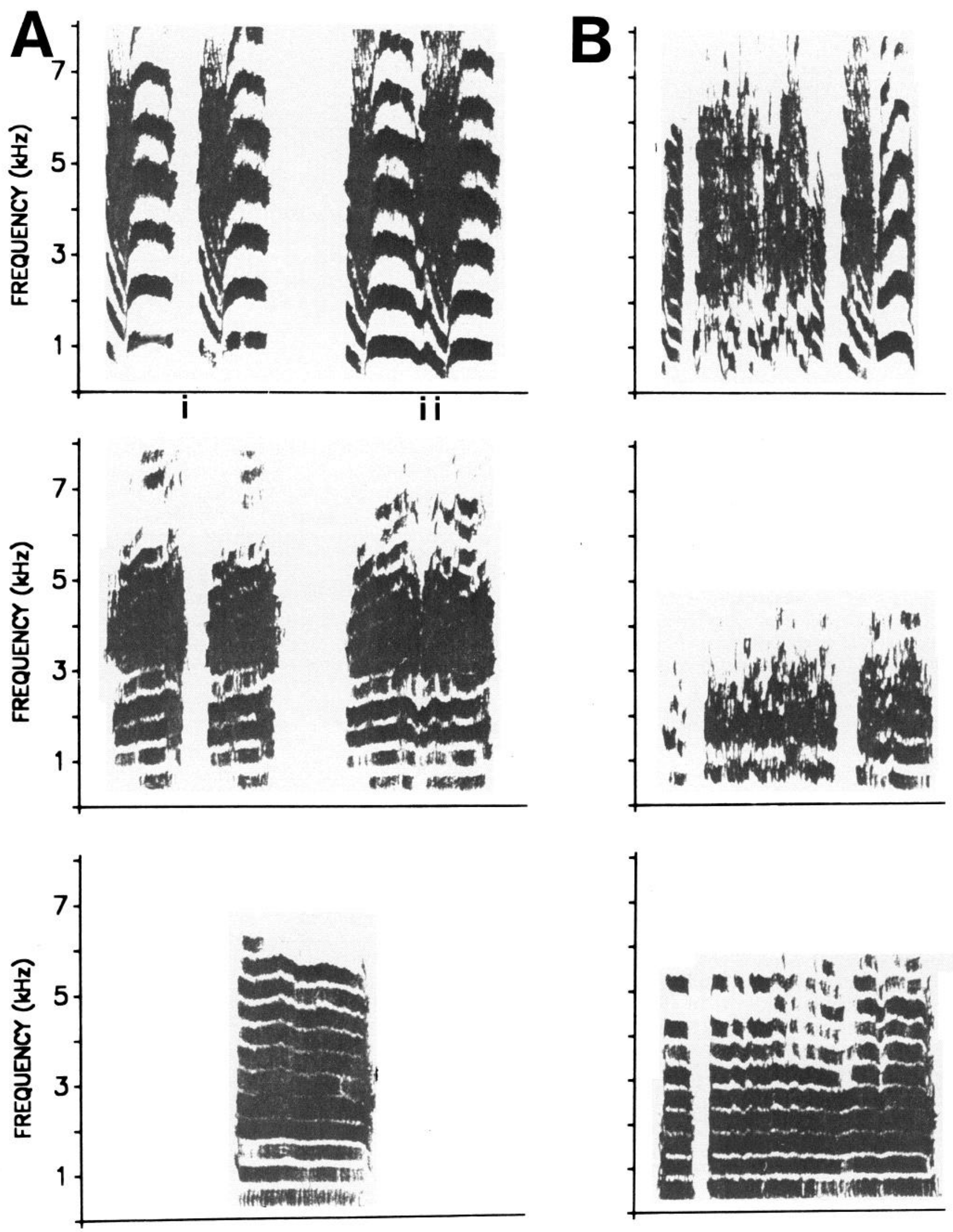
Table 3. Effect of bilateral lesions of an area including $\mathrm{HVC}$ on key features of the long calls of 3 females and 5 males

\begin{tabular}{|c|c|c|c|c|c|c|c|c|c|}
\hline \multicolumn{5}{|c|}{ Before $\mathrm{HVC}$ lesion } & \multicolumn{5}{|c|}{ After HVC lesion } \\
\hline Bird & FFM & $\mathrm{FF}$ & DUR & VAR & FFM & FF & DUR & VAR & Time \\
\hline \multicolumn{10}{|l|}{ Females } \\
\hline $\mathrm{Fa} 4$ & no & 516 & 328 & 1769 & no & $516 \quad(U=12.5)$ & $248^{* *}(z=4.3)$ & $3715 \quad(F=2.1)$ & 5 \\
\hline Db77 & no & 516 & $281^{b}$ & 7359 & no & $516 \quad(U-12.5)$ & $318 \quad(z=1.5)$ & $11,350 \quad(F=1.5)$ & $2-7$ \\
\hline W194 & no & 516 & 265 & 3227 & no & $516 \quad(U=12.5)$ & $309^{*}(z=2.4)$ & $6911 \quad(F=2.1)$ & $4-7$ \\
\hline \multicolumn{10}{|l|}{ Males } \\
\hline N15 & yes & 1419 & 193 & 147 & no & $606^{* *}(U=0)$ & $247^{* *}(z=5.5)$ & $1559^{* *}(F=10.6)$ & 14 \\
\hline R34 & yes & 1161 & 156 & 30 & no & $516^{* *}(U=0)$ & $238^{* *}(z=6.1)$ & $331^{* *}(F=11.0)$ & 4 \\
\hline R38 & no & 942 & 148 & 229 & no & $645^{* *}(U=0)$ & $239^{* *}(z=5.9)$ & $1058^{* *}(F=4.6)$ & 4 \\
\hline $\operatorname{Dg} 52$ & yes & 568 & 190 & 102 & no & $529 \quad(U=5)$ & $242^{* *}(z=6.0)$ & $291^{*}(F=2.9)$ & 11 \\
\hline $\mathrm{N} 21$ & yes & 477 & 169 & 22 & no & $516(U=5)$ & $164 \quad(z=0.6)$ & $257^{* *}(F=11.7)$ & 4 \\
\hline
\end{tabular}

Abbreviations and notes as in Table 1.

DG52), the lesions were very large, ranging from 1.5 to $1.7 \mathrm{~mm}$ in the medial-lateral plane, $1-1.3 \mathrm{~mm}$ in depth, and $1.5-2 \mathrm{~mm}$ in the anterior-posterior dimension, with at least $1.3 \mathrm{~mm}$ of lesion posterior to the lamina hyperstriatica. The fifth male (R38) received a smaller lesion that extended $1.3 \mathrm{~mm}$ in the medial-lateral planc, $1 \mathrm{~mm}$ in depth, and $1.3 \mathrm{~mm}$ in the anterior-posterior dimension starting at the lamina hyperstriatica. In all 5 cases, the neostriatum surrounding $\mathrm{HVC}$ and the overlying hippocampus were also lesioned, but Field $\mathrm{L}$ and NIF were spared. Any MAN fibers traveling by HVC on way to RA could have been affected. However, Bottjer et al. (1984) have shown that lesions of MAN in adult zebra finches have no effect on song syllables. A representative section from the male with the smallest lesion is shown in Figure $5 B$.

A chemical lesion of HVC was attempted in one male, but HVC was spared bilaterally. No clear lesion site was seen, but on both sides histological disruption was present along the rostral and ventral border of medial HVC. No changes in either this male's song or long calls were seen.

B. LONG CALL. Bilateral suction lesions of an area including HVC in 5 males had significant effects on all characteristic features of the long call. Long calls from one of these males before and after surgery are shown in Figure $8 B$. Changes in key features of the long call are displayed for each male in Table 3. All lesioned males produced calls that lacked the fast frequency modulation. Three of the 5 had an elevated fundamental frequency that dropped significantly and into the female range after HVC lesion. The other 2 males produced calls before surgery with fundamental frequencies in the female range; their fundamental frequency was not affected significantly by lesions including HVC. Finally, these lesions affected both the central tendency and the variability of long-call duration. Four of the 5 males showed a significant increase in mean duration following surgery. All 5 showed a significant increase in duration variability. c. soNG. After receiving bilateral lesions of an area including HVC, no male produced anything like his original song in syllable morphology and temporal pattern. By their posture, dancing, and bill-wiping behavior (Morris, 1953), males with such lesions seemed motivated to sing when presented with a female, although the most song-like vocalization produced by any of these males is displayed in Figure $8 C$. We have recorded similar vocalizations from intact males and females (unpublished observations).

\section{Nerve Iransection followed by central lesion}

Two males received central lesions after first undergoing ts nerve transection. In one (N40), RA was lesioned bilaterally. On both sides, medial RA was partially spared. The maximal extent of the lesion was $1.2 \mathrm{~mm}$, and it extended into the surrounding archistriatum. Long calls from this male before and after each procedure are shown in Figure 9. In the other male (N36), HVC was lesioned bilaterally. This was the smallest of all the HVC lesions, extending $0.8 \mathrm{~mm}$ in depth, $1.2 \mathrm{~mm}$ in the mediallateral plane, and $1.2 \mathrm{~mm}$ posterior to the lamina hyperstriatica. HVC was absent on both sides. In both males, the effects on the long call following central lesion were similar and are shown in Table 4.

As described above, nerve transection had no significant effect on duration variability but affected the other characteristic features of the male long call (Fig. 9, middle). After nerve transection, the fast frequency modulation resolved into a component of relative constant frequency separated from the original constant frequency segment by a brief drop in frequency. The mean duration increased slightly but significantly, and the fundamental frequency dropped significantly and into the female range in the male with an elevated fundamental frequency before surgery (Table 1).

After subsequent RA or HVC lesion, the remaining characteristic features of the long call were affected, resulting in long

Table 4. Effect of central lesions following nerve section on key features of the long calls in 2 males

After nerve and central lesion

\begin{tabular}{llllll}
\hline Bird & FFM & FF & DUR & VAR \\
\hline N40 & no & $542(U=12.5)$ & $208^{* *}(z=4.5)$ & $231^{* *}(F=13.6)$ & Time \\
N36 & no & $529(U=10)$ & $315^{* *}(z=5.7)$ & $4250^{* *}(F=142)$
\end{tabular}

N40 received a bilateral RA lesion. N36 received a bilateral HVC lesion. Data before and after nerve section are in Table 1. Abbreviations and notes as in Table 1. 

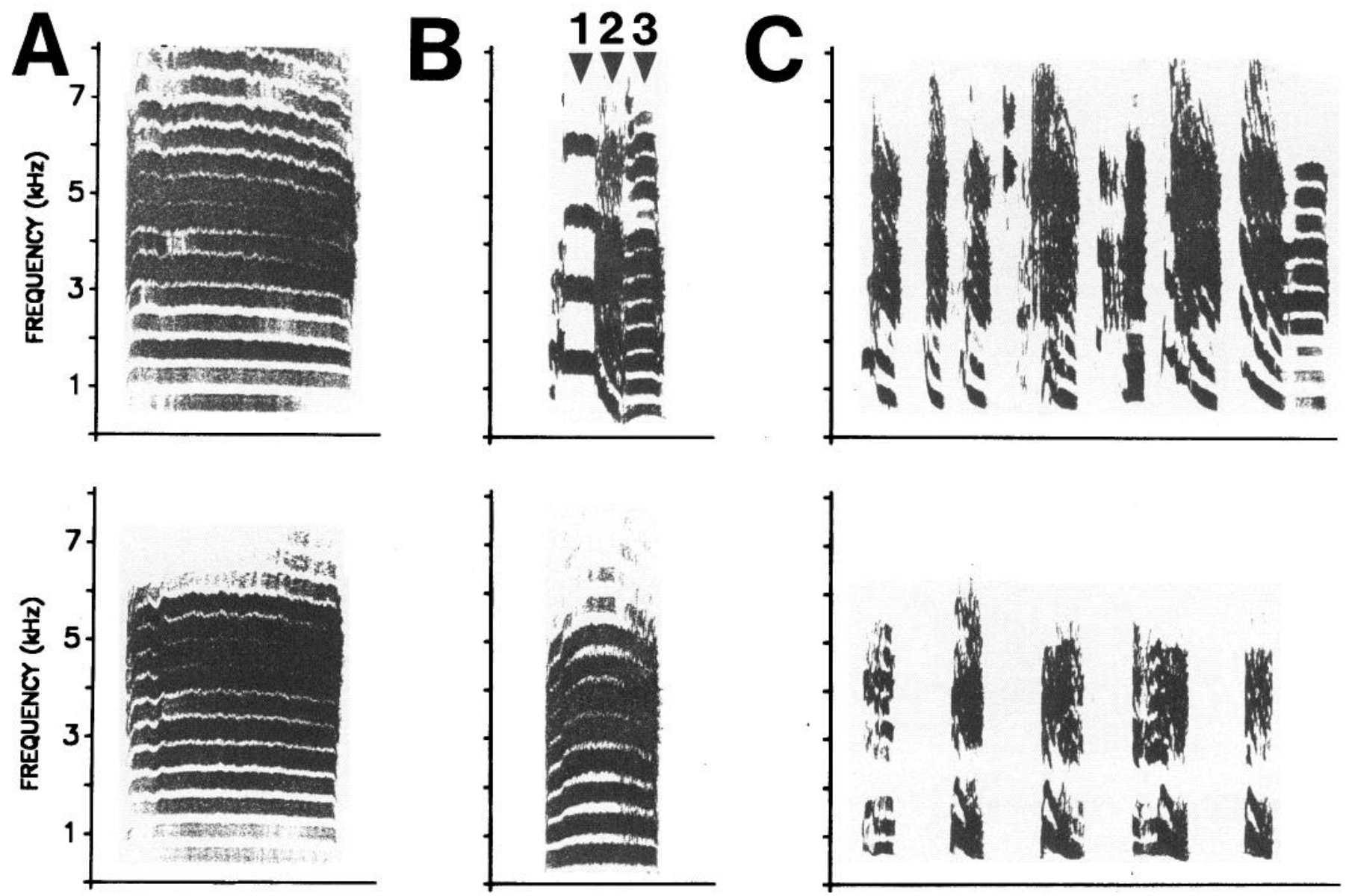

Figure 8. Effect of HVC lesions on long calls and song. A, Long calls of one female (W194) before (top) and after (bottom) bilateral HVC lesions, showing no change. B, Long calls of one male (N15) before (top) and after (bottom) bilateral HVC lesions. Before lesions, this call is complex: the first component has a high fundamental frequency (1), the second component is a downward fast frequency modulation (2), and the third component has a fundamental frequency in the female range (3). After HVC lesions, the call lost its fast frequency modulation, and the fundamental frequency of the first component dropped into the female range. $C$, Song of the same male before HVC lesion (top). The most songlike vocalization recorded after HVC lesion (bottom). This vocalization has neither the temporal organization nor the syllable morphology of the original song. Time bar, $150 \mathrm{msec}$.

calls that more nearly resembled the typical female long call (Fig. 9, bottom). After central lesion, the long call of both males was composed of just one longer constant-frequency component. Moreover, both the mean duration and duration variability increased significantly (Table 4). No further effect on fundamental frequency was seen in either male.

\section{Discussion}

\section{Peripheral and central contributions to the long call}

The learned features of the male long call depend critically on HVC, RA, and the ts nerve. Lesions of any of these 3 structures affect the downward fast frequency modulation and the maletypical fundamental frequency, while major changes in call duration occur only following central lesion. HVC and RA lesions had similar effects on the male long call; after both lesions, males produced long calls that were female-like in every respect. The typical female long call was not consistently affected by lesions of HVC, RA, or nerve transection.

However, the effectiveness of ts nerve section and central lesions depended on the acoustic structure of the vocalization, not on the sex of the caller, as the 2 males with female-like calls and the female with the male-like feature attest. Nerve section had no effect on the former, and RA lesions affected the latter. In general, lesions affected male-like but did not alter femalelike features of the long calls. While we have used the terms male- and female-like throughout this paper for heuristic value, we recognize that behaviorally, the distinction is not always absolute: male- and female-like features can occur in long calls of either sex.

\section{Problems of interpretation}

Most of our lesions of HVC and RA included surrounding brain areas as well. As a result, we cannot definitively exclude the possibility that areas near HVC or RA also play some role in producing the characteristic features of the male long call. However, 2 males (N36, R38) had lesions essentially limited to HVC; 2 others (N26, N95) had lesions essentially limited to RA; these lesions were sufficient to produce all the effects described. More- 

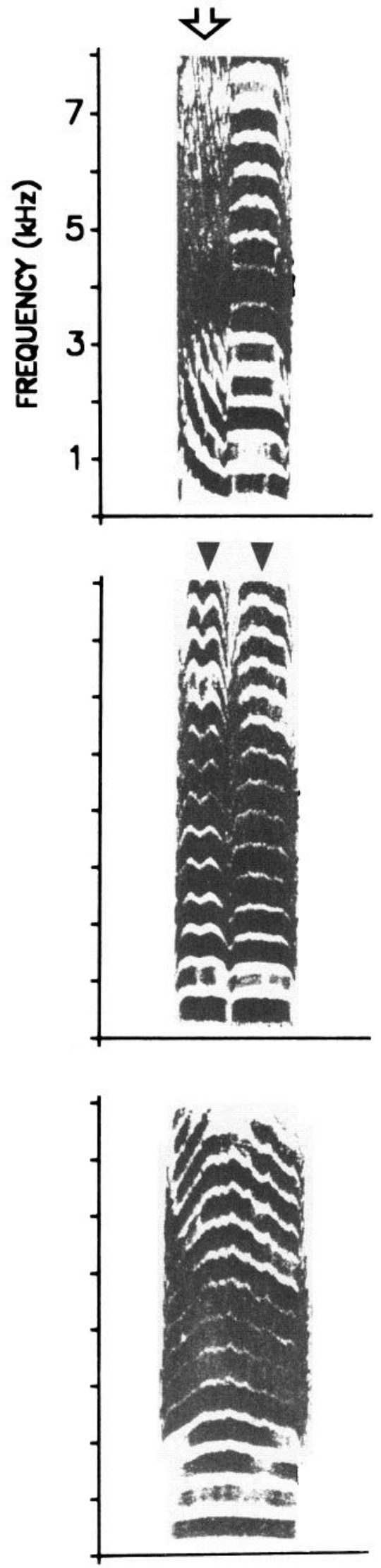

over, in one male, lesions that missed HVC had no effect on calls or song, and birds that received lesions limited to part of RA had partial effects on long calls and song. Taken together, these pieces of evidence strongly support the notion that HVC and RA are important for male long-call production.

Because of the difficulty in targeting HVC and RA in females, lesions of these nuclei were purposely very large to insure that HVC and RA were completely destroyed. To lesion RA in females, we made multiple penetrations, and thus may have damaged HVC in the process. Nonetheless, no central lesion of any size had clear effects on the female long call. We regard these results as strong evidence that $\mathrm{HVC}$ and the surrounding neostriatum, and RA and the surrounding archistriatum are not required for production of the female long call.

\section{Control of duration and timing in the call}

HVC and RA appear to play an essential role in determining the short and stable duration of the male long call. If sounds are produced only when sufficient air flows through the syrinx and trachea during expiration, as has been shown in canaries (Calder, 1970), then the duration of vocalization is linked to and limited by the duration of expiration. The variability in female call duration that we observed may be produced by different expiratory durations. In contrast, the short, stable duration of the male long call may occur because the male, when calling, explicitly controls either the duration of expiration or the period within each expiration when sound is produced. After HVC or RA lesion, the male call greatly increased in length and varied in duration like that of the female. After nerve section alone, duration variability remained the same, although the length increased slightly. Together, these results suggest that HVC and RA exert control over duration length and variability and thus influence, in some way, how vocalizations and respiration are coupled. However, this influence does not require syringeal innervation.

Additional evidence of a role for HVC and RA in the control of respiration during vocalization comes from those males whose calls had a fast frequency modulation. After nerve section, these calls appeared to be composed of 2 components (Fig. 9, middle), one corresponding to the period of the frequency modulation, the other corresponding to the unmodulated part of the call. After HVC or RA lesion, the call is composed of one long component (Fig. 9, bottom). If these components represent modulations of expiration within the call, then HVC and RA may not only influence overall call duration but also the finer structure of respiration underlying modulated calls.

Females normally have a small $\mathrm{HVC}$ and RA relative to males, and the connection from HVC to RA is either sparse or absent (Konishi and Akutagawa, 1985; Williams, 1985). If HVC and RA impart duration stereotypy to the male long call, as we suggested above, then females may produce long calis that vary in duration because these nuclei and this pathway do not function as in males. Whether these nuclei serve other behavioral

Figure 9. Effect of ts nerve section followed by RA lesions. Long calls of one male (N40) before (top), after nerve section (middle), and after subsequent bilateral RA lesions (bottom). After nerve section, the call lost its fast frequency modulation (open arrow) and appeared to be composed of 2 relatively constant frequency components (solid arrows). After subsequent RA lesions, the call appeared to be composed of only one component. Time bar, $150 \mathrm{msec}$. 
functions is unclear. They could simply represent the remnants of a developmental program that is only fully expressed in males. The 2 females with a small fast frequency modulation may have had a limited degree of masculinization of this pathway.

\section{Effects on song}

After complete HVC or RA lesions, no song was recorded from any male. Nottebohm et al. (1976) observed the same in 1 canary following bilateral electrolytic lesions of HVC. The most songlike vocalization we recorded from 1 male differed both in acoustic structure and temporal pattern from his original song. In contrast, after nerve section, while the song syllables lost their characteristic features, the temporal pattern was grossly preserved. Some syllables lengthened slightly, thereby increasing the overall duration of song. These results suggest that HVC, RA, and the ts nerves are required for the characteristic morphology of individual song syllables. In contrast, the pathway controlling the overall temporal pattern of song includes HVC and RA but bypasses the syrinx. A partial precedent for this result was seen following unilateral syringeal denervation in chaffinches (Nottebohm, 1971). Our results for song, together with those for the long call, show that active syringeal control is needed for the types of learned acoustic modulation seen in song and the male long call but not for vocalization in general.

\section{Long call as an experimental tool}

Because the long call is simpler acoustically and more easily crokcd than song but noncthclcss is lcarncd, we belicve it provides a useful tool to study the function of what have been traditionally called the song nuclei. For example, our results illustrate that HVC and RA control the production of the learned features of the male long call but not vocalization in general. Other nuclei implicated in song may also be important for long call production. For example, lesions of the MAN in juvenile zebra finches disrupt song learning (Botljer et al., 1984). Such lesions might interrupt male long-call learning as well. Examining the effects of MAN lesions on the long call may help specify the role MAN plays in vocal learning.

\section{Different brain pathways underlie the production of learned and unlearned vocalizations}

Our data suggest that the HVC-RA-nXIIts-syrinx pathway is essential for production of the learned vocalizations made by male zebra finches but is not needed for production of the unlearned female long call. Females must use another pathway for vocalization. It is likely this pathway exists in males as well: first, males with HVC and RA lesions produce long calls whose altered morphology closely resembles that of female calls; second, some intact males produce long calls that are femalelike in all features; finally, intact males produce a short call very similar in morphology, duration, and behavioral setting to one produced by females. Thus, 2 paths for vocalizations may coexist: one, that includes HVC and RA and is responsible for the learned features of both song and the long call; and another, more basic pathway, possibly located in the brain stem, that governs the production of unlearned vocalizations, including the unlearned components of otherwise learned vocalizations. Only male zebra finches imitate features of their long call and song (Immelmann, 1969; Zann, 1984). Only in males is the HVC to RA pathway fully developed anatomically and functionally.

A candidate component of a brain-stem vocalization pathway is the intercollicular complex (ICo), a midbrain structure implicated in call production in non-songbirds as well as songbirds (Seller, 1981). Stimulation of ICo in a variety of birds results in simple vocalizations, indicating that pathways descending from ICo are sufficient for such vocalizations (Seller, 1981). Anatomical outputs of ICo include the reticular formation (Nottebohm et al., 1976) and the parabrachial nuclear complex (Wild and Arends, 1987), both of which may provide links to respiratory centers that participate in vocalization. Moreover, the dorsomedial subregion (DM) of ICo projects to the motor neurons innervating the syrinx (Gurney, 1981).

Female long calls may be generated at the ICo level since our data indicate that the telencephalic pathway from HVC to RA is not necessary for female long-call production. In contrast, the learned features of male long calls (and song) require telencephalic participation. The telencephalic pathway from RA could serve different functions. For example, RA could affect acoustic structure by its direct projection to the syringeal motoneurons. In addition, RA could influence the midbrain pathway via its projection to DM. Call and song duration may be modulated by this DM pathway, since duration control ultimately depends on respiration, and ICo has access to both syringeal and respiratory mechanisms. In sum, the telencephalic pathway could function in parallel and/or in serial fashion with a more basic vocalization pathway.

In summary, the neural control of the zebra finch long call differs between the sexes. The simple acoustic structure of the female call docs not require syringcal inncrvation and may be governed by respiratory patterning. Similar mechanisms may be used by other bird species that lack vocal learning. The acoustic complexity of learned male zebra finch vocalizations results from active modulation of the expiratory airflow by the syrinx and other structures under the control of HVC and RA. This combination of respiratory and syringeal control enables complex vocalizations to be produced and imitated. The ability of telencephalic structures such as HVC and RA to modulate acoustically simpler vocalizations may have been acquired in concert with the evolution of vocal learning in birds.

\section{References}

Arnold AP (1980) Effects of androgens on volumes of sexually dimorphic brain regions in the zebra finch. Brain Res 185:441-444.

Bottjer SW, Glaessner SL, Arnold AP (1984) Forebrain lesions disrupt development but not maintenance of song in passerine birds. Science 224:901-903.

Calder WA (1970) Respiration during song in the canary (Serinus canarius). Comp Biochem Physiol 32:251-258.

Clayton NS (1988) Song tutor choice in zebra finches and bengalese finches: the relative importance of visual and vocal cues. Behavior 104:281-299.

DeVoogd TJ (1986) Steroid interactions with structure and function of avian song control regions. J Neurobiol 17:177-201.

Gurney ME (1981) Hormonal control of cell form and number in the zebra finch song system. J Neurosci 1:658-673.

Immelmann K (1969) Song development in the zebra finch and other estrildid finches. In: Bird vocalizations (Hinde RA, ed), pp 61-74. Cambridgc, UK: Cambridge UP.

Konishi M, Akutagawa E (1985) Neuronal growth, atrophy and death in a sexually dimorphic song nucleus in the zebra finch brain. Nature 315:145-147.

Morris D (1953) The reproductive behavior of the zebra finch (Poephila guttata), with special reference to pseudofemale behavior and displacement activities. Behavior 6:270-322.

Nottebohm F (1971) Neural lateralization of vocal control in a passerine bird I. Song. J Exp Zool 177:229-262. 
Nottebohm F (1972) The origins of vocal learning. Am Natur 106: 116-140.

Nottebohm F (1987) Birdsong. In: Encyclopedia of neuroscience (Adelman G, ed), pp 133-136. Boston: Birkhauser.

Nottebohm F, Arnold AP (1976) Sexual dimorphism in vocal control areas of the songbird brain. Science 194:211-213.

Nottebohm F, Stokes TM, Leonard CM (1976) Central control of song in the canary, Serinus canarius. J Comp Neurol 165:457-486.

Price PH (1979) Developmental determinants of structure in zebra finch song. J Comp Physiol Psychol 93:260-277.

Seller TJ (1981) Midbrain vocalization centres in birds. Trends Neurol $4: 301-303$.

Stokes TM, Leonard CM, Nottebohm F (1974) The telencephalon, diencephalon, and mesencephalon of the canary, Serinus canarius, in stereotaxic coordinates. J Comp Neurol 156:337-374.
Welty JC, Baptista L (1988) Songs, calls, and other sounds. In: The life of birds, pp 212-239. New York: Saunders College Publishing

Wild JM, Arends JJA (1987) A respiratory-vocal pathway in the brainstem of the pigeon. Brain Res 407:191-194.

Williams H (1985) Sexual dimorphism of auditory activity in the zebra finch song system. Behav Neural Biol 44:470-484.

Zann R (1984) Structural variation in the zebra finch distance call. Z Tierpsychol 66:328-345.

Zann R (1985) Ontogeny of the zebra finch distance call: I. Effects of cross-fostering to bengalese finches. Z Tierpsychol 68:1-23.

Zoloth S, Dooling RJ, Miller R, Peters S (1980) A microcomputer system for the synthesis of animal vocalizations. Z Tierpsychol 54: 151-162. 